\title{
Drug Repurposing: A Promising Tool in Drug Discovery Against CoV-19
}

\author{
Rohit Bhatia $^{1 *}$, Raj Kumar Narang ${ }^{1}$ and Ravindra Kumar Rawal ${ }^{2}$ \\ ${ }^{1}$ Department of Pharmaceutical Chemistry \& Pharmaceutics, ISF College of Pharmacy Moga, Punjab-142001, India \\ ${ }^{2}$ Department of Chemistry, Maharishi Markandeshwar, (Deemed to be University), Mullana-133207, Haryana, India \\ *Corresponding author: Rohit Bhatia, Department of Pharmaceutical Chemistry, ISF College of Pharmacy, Moga, Punjab-142001 \\ India
}

ARTICLE INFO

Received: 豐 July 02, 2020

Published: 幽 July 09, 2020

Citation: Rohit B, Raj Kumar N, Ravindra Kumar R. Drug Repurposing: A Promising Tool in Drug Discovery Against Cov-19. Biomed J Sci \& Tech Res 28(5)-2020. BJSTR. MS.ID.004702.
Keywords: Viral Epidemics; Corona virus; Drug Discovery; Proteins; Contagious

Abbreviations: SARS: Severe Acute Respiratory Syndrome; MERS: Middle East Respiratory Syndrome; ACE: Angiotensin-Converting Enzyme; HCV: Hepatitis C Virus; MT-DTI: Molecule Transformer-Drug Target Interaction; 2'-0-MTase: 2'-O-Ribose Methyltransferase

\section{Editorial}

Viral diseases have always appeared as a mystery and according to World Health Organization (WHO), these are the most serious public health issues. Past twenty years reveal the true picture of viral epidemics such as Severe Acute Respiratory Syndrome (SARS) caused by corona virus (SARS-CoV) during 2002-2003, H1N1 during 2009, Middle East Respiratory Syndrome (MERS) caused by MERS$\mathrm{CoV}$ in 2012 and the most dreadful COVID-19 caused by SARSCoV-2 from December, 2019 to till date [1]. According to latest WHO reports up to $10^{\text {th }}$ June, there are $71,45,539$ total confirmed cases of COVID-19 and approximately 105,621 people have lost their lives all over the world [2]. Drug and vaccine developers are continuously working in the search of a therapeutic candidate against COVID-19. Although mRNA based vaccine (developed by Moderna) has been launched in Phase I study and many biotech/pharma companies are working towards development of other vaccines; but even they get successful, most optimum time to launch a vaccine in market will take twelve to eighteen months [3].

Concerning the present situation of COVID-19 pandemic, the more immediate approach in drug discovery is drug repurposing. Drug repurposing is a methodology for making more value from an existing drug by targeting diseases by focusing on infections other than that for which it was initially proposed [4]. Repurposing of already approved therapeutic drugs towards new activity is an attractive approach to the researchers, medicinal chemists, clinicians, drug developers and public health organisations according to the need of the hour [5]. Therefore due to development time gap and clinical requirements for new therapeutic candidates, repurposing of existing drugs is the prominent solution for the emerged outbreak due to virus. This approach is time saving and also economic in comparison to de novo drug discovery techniques [6,7]. It is evident that SARS-CoV-2 is more contagious and transmissible than SARS-CoV and MRS-CoV [8]. CoV-19 belongs to beta type of corona virus family. Beta corona virus genome encodes several proteins which include glycosylated spike protein (S), AngiotensinConverting Enzyme 2 (ACE2) and non-structural proteins including RNA-dependent RNA polymerase (RdRp), coronavirus main protease (3CLpro), and papain-like protease (PLpro) [9-11]. The functions of all these proteins are well established already [12]. All the three members of corona virus family share structurally similar proteins which help in penetration and replication in host. Table 1 represents most relevant existing drugs along with their targets identified by chemical abstract service (CAS), which can be act as suitable candidates against COVID-19 for drug repurposing [13]. 
Table 1: Various existing drugs capable for drug repurposing against COVID-19.

\begin{tabular}{|c|c|c|c|c|c|}
\hline S.No & Drug & CAS No. & Target & $\begin{array}{l}\text { Possible mechanism of action on } \\
\text { COVID-19 }\end{array}$ & Approved for \\
\hline 1. & Lopinavir & $192725-17-0$ & $\begin{array}{l}\text { Viral proteases: } \\
\text { 3CLpro or PLpro }\end{array}$ & Inhibition of viral proteases & HIV infection \\
\hline 2. & Ritonavir & $155213-67-5$ & $\begin{array}{l}\text { Viral proteases: } \\
\text { 3CLpro or PLpro }\end{array}$ & Inhibition of viral proteases & HIV infection \\
\hline 3. & Darunavir & 206361-99-1 & $\begin{array}{l}\text { Viral proteases: } \\
\text { 3CLpro or PLpro }\end{array}$ & Inhibition of viral proteases & HIV infection \\
\hline 4. & Favipiravir & $259793-96-9$ & $\mathrm{RdRp}$ & Inaccurate viral RNA synthesis & Viral infection \\
\hline 5. & Remdesivir & $1809249-37-3$ & RdRp & $\begin{array}{l}\text { May block viral nucleotide synthesis to } \\
\text { stop viral replication }\end{array}$ & Ebola infection \\
\hline 6. & Ribavirin & $36791-04-5$ & $\mathrm{RdRp}$ & May stop viral RNA synthesis & Hepatitis C \\
\hline 7. & Galidesivir & $249503-25-1$ & $\mathrm{RdRp}$ & May terminate elongation of RNA strand & $\begin{array}{l}\text { Hepatitis C, Ebola, } \\
\text { Marbug virus }\end{array}$ \\
\hline 8. & Penciclovir & $39809-25-1$ & $\mathrm{RdRp}$ & May stop viral replication in host & Herpes infection \\
\hline 9. & Baloxavir marboxil & 1985606-14-1 & Endonuclease inhibitor & May prevent viral mRNA replication & Influenza infection \\
\hline 10. & Chloroquine & 54-05-7 & Endosome/ACE2 & $\begin{array}{l}\text { Can elevate endosomal pH and interfere } \\
\text { with ACE2 glycosylation }\end{array}$ & Antimalarial \\
\hline 11. & Baricitinib & 1187594-09-7 & JAK-Kinase & $\begin{array}{l}\text { May interfere with the inflammatory } \\
\text { processes }\end{array}$ & Rheumatoid arithritis \\
\hline 12. & Arbidol & $131707-23-8$ & S protein/ACE2 & $\begin{array}{l}\text { An inhibitor that may disrupt the binding } \\
\text { of viral envelope protein to host cells and } \\
\text { prevent viral entry to the target cell }\end{array}$ & Influenza infection \\
\hline 13. & Nitazoxanide & $55981-09-4$ & & May inhibit viral protein expression & $\begin{array}{l}\text { Helmintic, protozoal } \\
\text { infection }\end{array}$ \\
\hline
\end{tabular}

\section{Recent Reports on Drug-Repurposing Approach}

Many recent reports are available in literature where researchers have successfully screened out therapeutic candidates on the basis of drug repurposing approach. Zhou et al. has carried out network-based repurposing of drugs against SARSCoV-2. They carried out phylogenetic analysis of human corona virus whole genomes and found that SARS-CoV-2 have highest (79.7\%) nucleotide similarity with SARS-CoV and envelop and nucleopcapsid proteins have sequence similarities of $96 \%$ and 89.6\% respectively. They screened out 16 repurposable drugs against SARS-CoV-2 including melatonin, quinacrine, colchicine, mercaptopurine, irbesartan, camphor, toremiphene etc [14]. In another report, Singh et al. have also utilized drug repurposing approach for screening out inhibitors against 3C-like Proteinase (3CL pro) and 2'-O-Ribose Methyltransferase (2'-O-MTase). 3CL pro is responsible for proteolysis whereas 2'-0-MTase methylates the ribose at 2'-0 position. They screened out a library of 123 drugs by computing free energy binding and interaction with the target molecules. They concluded that Raltegravir, Paritaprevir, Bictegravir and Dolutegravir are excellent lead candidates for these crucial proteins and can be utilized for drug development against COVID-19 [15].

Kang et al. utilized Molecule Transformer-Drug Target Interaction (MT-DTI) for repurposing and identified marketed available drugs that could act on viral proteins of SARS-CoV-2. They calculated inhibitory potentials (Kd) of the drugs and reported that atazanavir (anti-HIV drug) revealed the excellentSARS-CoV-2 3C like proteinase inhibitory potential with Kd value of $94.94 \mathrm{nM}$ followed by remdesivir (113.13 $\mathrm{nM}$ ), efavirenz (199.17 $\mathrm{nM}$ ), ritonavir (204.05 nM), and dolutegravir (336.91 nM) [16]. Anderson et al. in their review have also reported 120 safe in human broad spectrum antiviral agents (BSAAs) from the freely accessible database among them 31 were found effective against COVID-19. Development of new as well as repositioned existing safe in man BSSAs may reduce the time and resources required for development virus specific drugs or vaccines [17]. Elfiky AA has tested existing antiHepatitis C Virus (anti HCV) drugs against CoV-19 RNA dependent RNA polymerase (RdRp) through sequence analysis, modelling and docking. He has also targeted the newely developed Wuhan HCoV RdRp model by anti-polymerase drugs. His findings indicated that Sofosbuvir, Ribavirin and Remidisivir have potentials in therapy of COVID-19 disease [18]. In a very recent report, Wagstaff et al. has evaluated the therapeutic efficacy of Ivermectin against CoV19. In an in vitro setup utilizing Vero-hSLAM cells, they found that Ivermectin causes 5000-fold reduction in replication of viral RNA within two hours [19].

\section{Strategies for Drug Repurposing against COVID-19}

There are several in silico techniques available which are based upon available databases so as to get information about pre existing drugs. Useful databases for srug information include PubChem, ChEMBL, DrugBank, ZINC, BindingDB, SEA, DR. PRODIS, Cmap V2, LINCS, TCGA, GEO, NPC, PD2, Pharos, Clinical Trials, SIDER, Offsides, 
FAERS and DvD [20]. Beyond this various molecular modelling tools such as docking utilizing protein data bank can also be utilized to study new drug-receptor interactions of existing drugs with SARS-CoV-2 targets [21]. Computational methods have a variety of algorithms and scoring functions to access the efficacy of the wide variety of drugs which form the basis of selection of a drug for the motive of repurposing. Various databases are also available to study viral genomes are NCBI-NIH, RVBD, VISDB, viruSITE, KEGG VIRUS etc. Drug repurposing can also be achieved by in vitro methods, in vivo methods as well as through enzyme inhibition assays.

Although, drug repurposing represents an immediate and cost effective approach in drug discovery according to the need of the hour against COVID-19; but it is also associated with certain challenges such as structure based design of specific drugs or vaccines. Generally, repurposed single drugs are not sufficiently potent; therefore a cocktail combination approach has to be implemented. Another issue with repurposed drugs is patent protection under the current regulatory guidelines. But as the new drug or vaccine will take sufficient time to be launched; drug repurposing is the most promising tool in the current time. Researchers, drug developers, clinicians and pharmaceutical sectors should work on this approach so as to explore the therapeutic potentials of the existing drugs against COVID-19 pandemic.

\section{References}

1. Cascella M, Rajnik M, Cuomo A, Scott C Dulebohn, Raffaela Di Napoli (2020) Features, Evaluation and Treatment Coronavirus (COVID-19) StatPearls.

2. (2020) Coronavirus disease (COVID-19) outbreak.

3. Ryan Cross (2020) Gilead and Moderna lead on coronavirus treatments. C\&en.

4. Cheng F, Murray JL, Rubin DH (2016) Drug repurposing: new treatments for Zika virus infection? Trends Mol Med 22(11): 919-921.

5. Dyall J, Christopher M Coleman, Brit J Hart, Thiagarajan Venkataraman, Michael R Holbrook, et al. (2014) Repurposing of clinically developed drugs for treatment of Middle East respiratory syndrome coronavirus infection. Antimicrob. Agents Chemother 58(8): 4885-4893.

6. Cheng F (2019) In silico oncology drug repositioning and polypharmacology. Methods Mol Biol 1878: 243-261.

ISSN: 2574-1241

DOI: $10.26717 /$ BJSTR.2020.28.004702

Rohit Bhatia. Biomed J Sci \& Tech Res

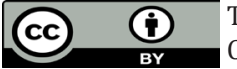

This work is licensed under Creative Commons Attribution 4.0 License

Submission Link: https://biomedres.us/submit-manuscript.php
7. Cheng F, Hong H, Yang S, Wei Y (2017) Individualized network-based drug repositioning infrastructure for precision oncology in the panomics era. Brief Bioinformatics 18(4): 682-697.

8. Paules CI, Marston HD, Fauci AS (2020) Coronavirus infections-More than just the common cold. JAMA.

9. Prajapat M, Sarma P, Shekhar N, Avti P, Sinha S, et al. (2020) Drug targets for corona virus: A systematic review. Indian J Pharmacol 52(1): 56-65.

10. Hilgenfeld R (2014) From SARS to MERS: Crystallographic studies on coronaviral proteases enable antiviral drug design. FEBS J 281(18): 4085-4096.

11. Wang H, Xue S, Yang H, Chen C (2016) Recent progress in the discovery of inhibitors targeting coronavirus proteases. Virol Sin 31(1): 24-30.

12. Bhatia R, Narang RK, Rawal RK (2020) A Summary of Viral Targets and Recently Released PDB IDs of SARS-CoV-2. The Open Virol J 14: 7-8.

13. Cynthia Liu, Qiongqiong Zhou, Yingzhu Li, Linda V Garner, Steve P Watkins, et al. (2020) Research and Development on Therapeutic Agents and Vaccines for COVID-19 and Related Human Coronavirus Diseases. ACS Central Science 6(3): 315-331.

14. Zhou Y, Hou Y, Jiayu Shen, Yin Huang, William Martin, et al. (2020) Network-based drug repurposing for novel coronavirus 2019-nCoV/ SARS-CoV-2. Cell Discovery 6: 14 .

15. Khan RJ, Kumar JR, Gizachew Muluneh Amera, Monika Jain, Ekampreet Singh, et al. (2020) Targeting Novel Coronavirus 2019: A Systematic Drug Repurposing Approach to Identify Promising Inhibitors Against 3C-like Proteinase and 2'-0-Ribose Methyltransferase. ChemRxiv.

16. Beck B, Shin B, Choi Y, Park S, Kang K (2020) Predicting commercially available antiviral drugs that may act on the novel coronavirus (SARS-CoV-2) through a drug-target interaction deep learning model. Computational and Structural Biotechnology Journal 18: 784-790.

17. Andersen PI, Ianevski A, Lysvand H, Astra Vitkauskiene, Valentyn Oksenych, et al. (2020) Discovery and development of safe-in-man broad-spectrum antiviral agents. Int J Infect Dis 93: 268-276.

18. Elfiky AA (2020) Anti-HCV , nucleotide inhibitors, repurposing against COVID-19. Life Sciences 248.

19. Caly L, Druce JD, Catton MG, Jans DA, Wagstaff KM (2020) The FDAapproved Drug Ivermectin inhibits the replication of SARS-CoV-2 in vitro, Antiviral Research 178

20. Hodos R, Kidd BA, Shameer K, Readhead BP, Joel T Dudley (2016) In silico methods for drug repurposing and pharmacology: Computational approaches to drug repurposing and pharmacology. Wiley Interdisciplinary Reviews: Systems Biology and Medicine 8(3): 186-210.

21. Canrong Wu, Yang Liu, Yueying Yang, Peng Zhang, Wu Zhong, et al. (2020) Analysis of therapeutic targets for SARS-CoV-2 and discovery of potential drugs by computational methods, Acta Pharmaceutica Sinica B 10(5): 766-788.

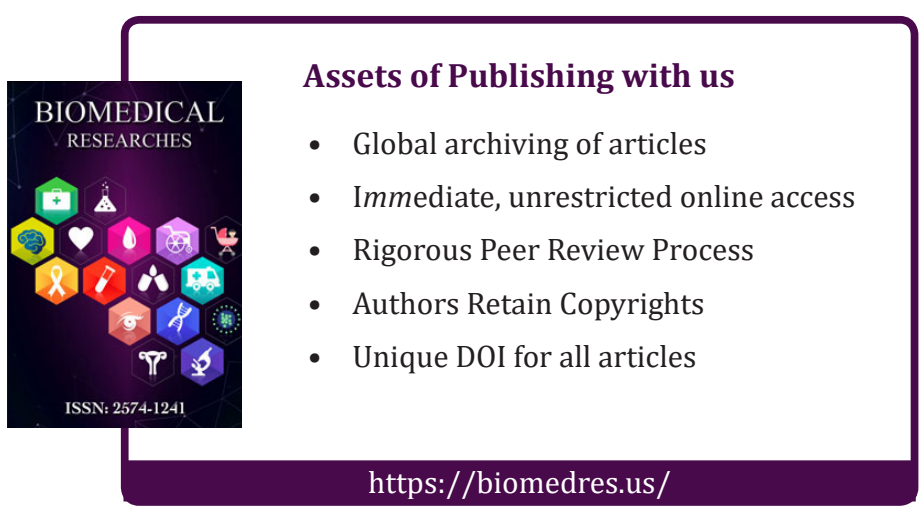

